\title{
Night time resistance exercise alters muscular IL-6-related protein signaling, but not muscle growth after 10 weeks of resistance training in male rats
}

\author{
Chung-Pu Chi ${ }^{1,2}$, Chieh-Wen $\mathrm{Hou}^{3}$, Yu-You Wu ${ }^{3}$, Tong-Hong Wang ${ }^{4}$ and $\mathrm{Szu}-\mathrm{Hsien} \mathrm{Yu}^{5}$ \\ ${ }^{1}$ Center of General Education, Taipei Medical University, Taipei, Taiwan, Republic of China \\ ${ }^{2}$ School of Nutrition and Health Sciences, Taipei Medical University, Taipei, Taiwan, Republic of China \\ ${ }^{3}$ Department of Exercise Science, University of Taipei, Taipei, Taiwan, Republic of China \\ ${ }^{4}$ Tissue Bank, Chang Gung Memorial Hospital, Tao-Yuan, Taiwan, Republic of China \\ ${ }^{5}$ Department of Leisure Industry and Health Promotion, National Ilan University, I-Lan, Taiwan, Republic of China
}

\begin{abstract}
The present study investigated the time-of-day effects on acute response and chronic adaptations to resistance exercise (RE) in rat skeletal muscle. Male rats were divided into Early and Late training groups and performed climbing RE during the first or last hour of the active (dark) period, respectively. The first experiment measured muscle mass and strength after a 10-week climbing training program. The second experiment examined inflammatory signaling response and satellite cell (SC) numbers following an acute bout of RE. The results showed no significant differences between rats training at early and late active periods in relative muscle weight (muscle-to-weight ratio), cross sectional area (CSA) and strength. The acute study observed increased STAT1 phosphorylation, oxidative stress (2-thiobarbituric acid reacting substances, TBARS), SCs ( $\mathrm{Pax} 7^{+}$), neutrophils (His $48^{+}$) and macrophages $\left(\mathrm{CD}^{+} 8^{+}\right)$, and decreased interleukin 6 (IL-6) protein expression of skeletal muscle relative to non-exercise control after an acute bout of RE. Interestingly, higher plasma IL-6 and STAT3 phosphorylation response was observed in the late training group when compared to the early training group after an acute bout of RE. The results of this study suggest that animals can adapt to resistance training at different time-of-day, by modulating inflammatory signaling of skeletal muscle.
\end{abstract}

Key words: Circadian variation — Satellite cell — Training adaptation

\begin{abstract}
Abbreviations: CSA, cross sectional area; FDP, flexor digitorum profundus, FHL, flexor hallucis longus; IL-6, interleukin 6; PBS, phosphate buffered saline; PVDF, polyvinylidene difluoride; RE, resistance exercise; RT, resistance training; SC, satellite cell; STAT, signal transducer and activator of transcription; T/C ratio, testosterone/corticosterone ratio; TBARS, 2-thiobarbituric acid reacting substances; TOD, time-of-day; TTBS, tris-tween-buffered saline.
\end{abstract}

\section{Introduction}

Resistance training (RT) has been recognized as an effective approach to improve muscle mass (Gonzalez et al. 2016). Little is known regarding the optimal time-of-day (TOD) to

Correspondence to: Szu-Hsien Yu, Department of Leisure Industry and Health Promotion, National Ilan University, No. 1, Sec. 1, Shennong Rd., Yilan City, Yilan County 260, Taiwan, Republic of China E-mail: shyu0918@gmail.com conduct resistance training. The literature on this subject is limited and presents conflicting results. Earlier studies have shown that resistance training in the morning and afternoon periods produce similar gains in muscle strength, volume and cross-sectional area (CSA) after an 10-week (Sedliak et al. 2009) or 11-week (Sedliak et al. 2018) training period on untrained subjects. However, in another study, greater muscle CSA improvement was observed when RT was conducted in the morning compared to the evening (Küüsmaa et al. 2016). 
Inflammation plays an important role in eliminating injured cells after harmful stimulation (Tidball 2017) and it is one of the possible factors responsible for muscle hypertrophy against exercise-induced muscle damage (Soltow et al. 2006; Novak et al. 2009). During the early phase of inflammation after exercise, neutrophils $\left(\mathrm{His} 48^{+}\right)$and phagocytic macrophages $\left(\mathrm{CD}^{+} 8^{+}\right)$are recruited to remove damaged muscle cells and free radicals are released leading to interleukin 6 (IL-6) increase (Fischer et al. 2004). Satellite cells (SCs) activation during inflammation is essential for the muscle recovery and hypertrophy (Almada et al. 2016). SCs are progenitor cells located between the plasma membrane and basal lamina of mature myofibers (Tierney et al. 2016). SCs proliferate and differentiate after resistance training, evidenced by increased numbers of SC and myonuclei in muscle (Bellamy et al. 2014). Release of IL-6 from damaged muscle cells is associated with exercise-induced SC-dependent muscle growth (Hiscock et al. 2004; Begue et al. 2013). IL-6 knock-out diminished macrophage infiltration in cardiotoxin-induced injury model (Zhang et al. 2013), and attenuated hypertrophic response and myonuclei accretion after compensatory hypertrophy (Serrano et al. 2008). At cellular level, IL-6-induced SC activation is dependent on signal transducer and activator of transcription (STAT) signaling (Toth et al. 2011). IL-6 leads subsequently to phosphorylation of STAT3 (pSTAT3), which triggers muscle growth-related gene expression and stimulates proliferation of SC (Toth et al. 2011; Trenerry et al. 2011). STAT3 phosphorylation is associated with the activation and proliferation of SCs following acute exercise-induced muscle damage amongst humans (Toth et al. 2011). In addition, the STAT1/STAT3 signaling pathway is required for SC proliferation (Sun et al. 2007). IL-6 release appears to be related to metabolic states (Pedersen et al. 2007) and the magnitude of IL- 6 release maybe associated with the resulting degree of adaptation in muscle (Serrano et al. 2008). To our knowledge, it is currently unknown whether IL-6 response and muscle adaptation can changed when resistance training is conducted at different time-of-day.

Therefore, the main purpose of the present study is to investigate the time-of-day effects on chronic adaptations of muscle after 10 weeks of resistance training in young male rats. To examine systemic and peripheral adaptation, plasma IL-6, testosterone and corticosterone, muscle inflammatory cell invasion, SC proliferation and IL-6/STAT1/STAT3 signaling proteins were measured after an acute bout of resistance exercise. Long term effects on muscle mass and strength were investigated. We hypothesized that acute responses in inflammation and SC recruitment in skeletal muscle will vary to adapt to resistance exercise at different TOD. However, the long-term effects of resistance training on muscle mass and strength will remain unchanged regardless of training TOD.

\section{Material and Methods}

\section{Animals}

Male Sprague Dawley (SD) rats $(n=104)$ were purchased from LASCO Corporation (Taipei, Taiwan) at 8 weeks of age and housed in the Animal Center of the University of Taipei (Taipei, Taiwan). Animals were housed at a constant $22 \pm 2{ }^{\circ} \mathrm{C}$ and $50 \%$ relative humidity, and maintained with 12:12 hours (6:00-18:00) dark/light cycle. All rats had ad libitum access to standard rat chow (PMI Nutrition International, Brentwood, MO, USA) and tap water. This study was approved by the Animal Care and Use Committee at the University of Taipei (Approval Number: UT 104001). Sacrifice of all animals was performed under Zoletil and Xylazine anesthesia according to the Institutional Animal Care and Use Committee guideline.

\section{Experimental design}

The chronic training study was designed to assess long-term adaptation in muscle mass and strength, 34 rats were trained using a ladder climbing resistance exercise protocol for 10 weeks during different time-of-day: early active period (Early, $n=10$ ) and late active period (Late, $n=10$ ) of wake/sleep cycles, together with a non-exercise control group (Control, $n=14$ ). Early active period is defined as performing resistance training (RT) during the first $1 \mathrm{~h}$ of dark period (active period of rat biological clock), whereas late periods refers to exercise started from $1 \mathrm{~h}$ before the end of dark period. Three days after 10 weeks of resistance training, muscle strength of all rats were determined. Rats were anesthetized via an intraperitoneal injection of Zoletil and Xylazine 3 days after the muscle strength measurement. Flexor digitorum profundus (FDP), flexor hallucis longus (FHL) muscle and epididymal fat were dissected and weighed. Muscles were freeze-clamped and frozen in liquid nitrogen until tissue analysis.

The acute exercise study was designed to determine systemic and peripheral responses, rats were challenged with an acute bout of resistance exercise at different time-of-day. All rats were divided randomly into Early $(n=35)$ and Late ( $n=35$ ) groups. To determine the time-of-day effects on inflammatory responses, rats of each group were sacrificed $2 \mathrm{~h}$ (E2) (Early, $n=9$; Late, $n=8$ ), 6 h (E6) (Early, $n=9$; Late, $n=10$ ) and $24 \mathrm{~h}$ (E24) (Early, $n=9$; Late, $n=9$ ) after exercise against sedentary ( $\mathrm{S}$ ) control (Early, $n=8$; Late, $n=8$ ). FDP, FHL muscle and blood were collected under anesthesia at the same time points for each group.

\section{Resistance exercise}

Rats performed resistance exercise on a training apparatus adapted from Begue et al. (2013). A 1 meter ladder (inclined 
at 85 degree slope) with $2 \mathrm{~cm}$ grid steps and was used. Seven days before the acute resistance exercise and chronic training intervention protocol started, rats were familiarized by climbing from the bottom to the top of the ladder without additional weight loading for seven days, three times a day. In order to adjust exercise intensity over time, tubes weighted with lead were attached to the base of each rat's tail.

The chronic training and acute exercise protocol were modified from Begue et al. (2013). The training protocol required rats to complete 10 weighted climbing exercise repetitions every two days. The initial training weight attached to each rat was $50 \%$ of the individual rat's body weight. Training weight was increased by $10 \%$ previous loading weight if, during the rat's preceding training session, it was able to complete 10 repetitions. Else, the training weight remained the same in future sessions until the rat complete the required 10 repetitions. The average loading reached $180 \%$ of final body weight after 10 weeks of training. The acute protocol required rats to perform a single bout of exercise, rats climbed 4 times with a load of $25 \%$ of body weight, 4 times at $50 \%$, 4 times at $75 \%$ and 6 times at $100 \%$. Two minutes rest was allowed between each repetition.

\section{Muscle strength}

Muscle strength in this study was defined as maximal tolerable weight load during climbing and measured 3 days after the last training session. In order to avoid the influence of circadian variation (Chtourou et al. 2012), the muscle strength measurement of all animals were performed at the middle of wake cycle. The testing protocol was modified from Hornberger Jr. et al. (2004). After climbing 3 times without additional weight, rats climbed the ladder with progressively increased loads until the weight could no longer be sustained.

\section{Hormones}

Blood samples were centrifuged at 3,000 rpm for $10 \mathrm{~min}$, supernatant (plasma) was obtained and stored at $-80^{\circ} \mathrm{C}$ until analysis. Testosterone, corticosterone and IL- 6 concentrations were measured using Testosterone ELISA kit (Cayman, Ann Arbor, MI, USA), Corticosterone ELISA kit (IBL-America, Minneapolis, MN, USA) and IL6 ELISA kit (Bio Legend, San Diego, CA, USA), according to manufacturer instructions.

\section{Histology and immunohistochemistry (IHC)}

Histology and immunohistochemistry staining were conducted by pathologists of Tissue Bank in Chang Gung Memorial Hospital (New Taipei City, Taiwan). FHL muscle tissues were fixed in formalin immediately after sacrifice.
Fixed muscle samples were then embedded in paraffin and sliced into $10 \mu \mathrm{m}$ sections. In the chronic training study, hematoxylin and eosin ( $\mathrm{H} \& \mathrm{E})$ staining was used to observe tissue histology. Immunochemical analysis was performed for the acute study, cell surface markers His48, CD68 and Pax7 were used to evaluate neutrophils, macrophages and satellite cells as in previous studies (Mikkelsen et al. 2009). Fixed muscle sections were incubated with mouse monoclonal antibody against His48 (1:150 dilution) (Abcam, Cambridge, UK), CD68 (1:150 dilution) (Abcam, Cambridge, UK) and Pax7 (1:150 dilution) (Bioss, Woburn, MA, USA) for $2 \mathrm{~h}$ at room temperature. After 3 washes with phosphate buffered saline (PBS), mouse and rabbit specific HRP/DAB (ABC) detection kits (Abcam, Cambridge, UK) were used to visualize positive signals from target cells. Image J software (NIH, Bethesda, MD, USA) for image analysis was used to measure the cross-sectional area of myofibers and count the number of His48-, CD68- and Pax7- positive cells. In each muscle section, we counted myofibers from different areas of the section; the total myofiber count was more than 400 .

\section{Western blotting}

FDP muscle samples ( $50 \mathrm{mg}$ ) were homogenized in $0.65 \mathrm{ml}$ homogenization buffer containing $20 \mathrm{mM}$ HEPES, $2 \mathrm{mM}$ EGTA, $1 \mathrm{mM}$ EDTA, $100 \mathrm{mM} \mathrm{KCl}$ and $1 \mathrm{mM}$ DTT. Homogenates of each sample were centrifuged at 14,000 rpm for $10 \mathrm{~min}$ at $4^{\circ} \mathrm{C}$, and the supernatant was added to $4 \mathrm{X}$ Laemmli sample buffer (62.5 mM Tris-HCl, pH 6.8, 10\% glycerol, 1\% LDS, 0.005\% Bromophenol Blue) (Bio-Rad Laboratories, Hercules, CA, USA) in a 1:3 ratio for Western blotting analysis. $10 \mu \mathrm{g}$ protein was separated by $10-12 \%$ sodium dodecyl sulfate-polyacrylamide gel electrophoresis (SDS-PAGE) and then transferred on to a polyvinylidene difluoride (PVDF) membrane (GoalBio, Taipei, Taiwan) by wet transfer system (Bio-Rad Laboratories, Hercules, CA, USA). After blocking with 5\% skimmed milk in Tris-TweenBuffered Saline (TTBS) buffer for $1 \mathrm{~h}$, PVDF membranes were incubated with primary antibodies in TTBS buffer for $12 \mathrm{~h}$ at $4^{\circ} \mathrm{C}$. The primary antibodies were IL-6 (1:1000 dilution) (Novus, Littleton, CO, USA), pSTAT1 (1:1000 dilution) (Cell signaling, Beverly, MA, USA), STAT1 (1:1000 dilution) (Cell signaling, Beverly, MA, USA), pSTAT3 (1:1000 dilution) (Abcam, Cambridge, MA, USA) and STAT3 (1:1000 dilution) (Abcam, Cambridge, MA, USA). After three washes with TTBS buffer, PVDF membranes were incubated with antimouse (Sigma, St Louis, MO, USA) or anti-rabbit secondary antibody (Cell Signaling Technology, Beverly, MA, USA). Enhanced chemiluminescent HRP substrate (PerkinElmer Life and Analytical Sciences, Shelton, CT, USA) was used to detect the antibody-bound protein. Western blot bands were quantified using ChemiDoc XRS+ System (BioRad, Hercules, CA, USA). Glyceraldehyde-3-Phosphate Dehydrogenase 
A

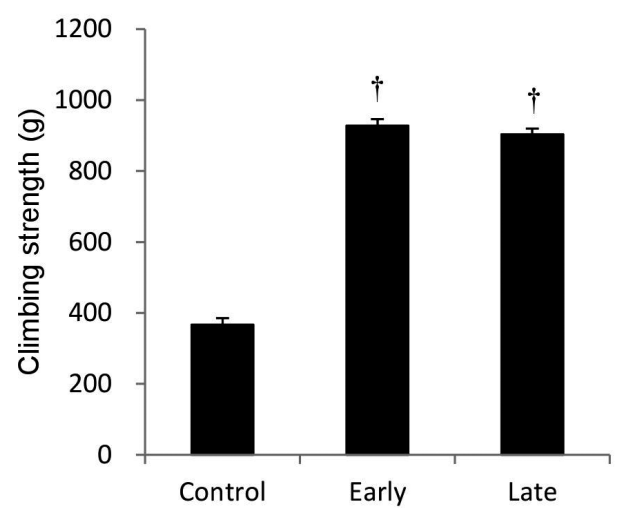

B

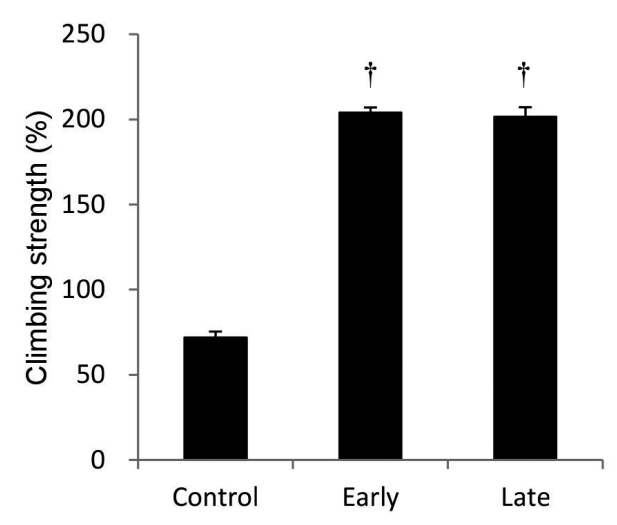

Figure 1. Muscle strength. Bars represent the absolute (A) and relative (B) climbing strength in the Early and Late groups. All data are presented as the mean \pm SE. ${ }^{\dagger} p<0.05$ vs. Control group.
(GAPDH) expression levels were determined and used as an internal control.

\section{Statistical analysis}

All values are expressed as means \pm standard error (SE). Because of the small sample size, non-parametric statistical methods were applied. In the chronic training study, the Kruskal-Wallis $\mathrm{H}$ test was used to compare the medians of all variables across the three study groups. In the acute exercise study, the Kruskal-Wallis $\mathrm{H}$ test was used to compare median values between different time points within groups, and Mann-Whitney U test was used to compare median values between the Early and Late groups in same time point. A level of $p<0.05$ was set for statistical significance of difference.

\section{Results}

Relative muscle weights (muscle-to-weight ratio) of FDP and FHL of both training groups (Early and Late groups) were significantly greater than those of the Control group. On the contrary, epididymal fat mass of both training groups were significantly lower than that of the Control group (Table 1). This 10-week training protocol increased climbing strength by $187 \%$ in the Early group and $192 \%$ in the Late groups compared to the Control group (Fig. 1). No significant difference in muscle mass and strength were found between the Early and Late groups. To confirm this resistance training induced muscular hypertrophy, CSA, myonuclei numbers and myonuclear domain were measured (Table 2). Climbing training increased myofiber CSA by $19 \%$ and $18 \%$ in the Early and Late groups, respectively, when compared to the Control group. No significant difference in myofiber CSA were found between the Early and Late groups. However, numbers of myonuclei per fiber did not differ among the three groups after 10 weeks of resistance training, suggest- ing that incorporation of new nuclei into the myofibers did not occur (Table 2).

To evaluate the inflammatory response to acute resistance exercise in skeletal muscle, we examined His48 and CD68-positive cell numbers in FHL muscle sections (Fig. 2). His48-positive cells of both training groups increased until $6 \mathrm{~h}$, and returned to baseline $24 \mathrm{~h}$ after exercise (Fig. 2A). In both training groups, numbers of CD68-positive cells were

Table 1. Body mass and tissue weight of muscles (FHL and FDP) and fat after 10 weeks of resistance training

\begin{tabular}{lccc}
\hline & \multicolumn{3}{c}{ Group } \\
\cline { 2 - 4 } & Control & Early & Late \\
\hline Total body mass (g) & $513 \pm 10$ & $455 \pm 9^{\dagger}$ & $450 \pm 9^{\dagger}$ \\
\hline FHL (g) & $0.74 \pm 0.03$ & $0.81 \pm 0.02$ & $0.83 \pm 0.02$ \\
FHL (\%) & $1.45 \pm 0.03$ & $1.77 \pm 0.05^{\dagger}$ & $1.85 \pm 0.04^{\dagger}$ \\
FDP (g) & $0.28 \pm 0.06$ & $0.30 \pm 0.01$ & $0.28 \pm 0.01$ \\
FDP (\%) & $0.53 \pm 0.01$ & $0.66 \pm 0.02^{\dagger}$ & $0.63 \pm 0.02^{\dagger}$ \\
Fat (g) & $7.0 \pm 0.4$ & $5.2 \pm 0.4^{\dagger}$ & $5.2 \pm 0.5^{\dagger}$ \\
Fat (\%) & $1.36 \pm 0.07$ & $1.14 \pm 0.08^{\dagger}$ & $1.15 \pm 0.10^{\dagger}$ \\
\hline
\end{tabular}

${ }^{\dagger}$ significantly different compared to Control group $(p<0.05)$. FHL, flexor hallucis longus; FDP, flexor digitorum profundus.

Table 2. Muscle fiber cross-sectional area (CSA), nuclei/fiber and myonuclear domain of FHL muscle after 10 weeks of resistance training

\begin{tabular}{lccc}
\hline & \multicolumn{3}{c}{ Group } \\
\cline { 2 - 4 } & Control & Early & Late \\
\hline Myofiber CSA $\left(\mu \mathrm{m}^{2}\right)$ & $1642 \pm 71$ & $1959 \pm 152^{\dagger}$ & $1942 \pm 88^{\dagger}$ \\
Nuclei perfiber (number) & $1.28 \pm 0.03$ & $1.30 \pm 0.04$ & $1.27 \pm 0.06$ \\
$\begin{array}{l}\text { Fiber area per nucleus } \\
\left(\mu \mathrm{m}^{2}\right)\end{array}$ & $1307 \pm 34$ & $1542 \pm 58^{\dagger}$ & $1565 \pm 85^{\dagger}$ \\
\hline
\end{tabular}

${ }^{\dagger}$ significantly different compared to Control group $(p<0.05)$. 
elevated at 2, 6 and $24 \mathrm{~h}$ after exercise (Fig. 2B). Similar to His48, TBARS levels in FDP muscle increased significantly until $6 \mathrm{~h}$, and returned to baseline $24 \mathrm{~h}$ after exercise (Fig. 2C). However, no significant difference in His $48^{+}, \mathrm{CD}^{+} 8^{+}$ cells and TBARS levels were found between the Early and Late groups at all measured time points.

SCs were evaluated by measuring Pax7-positive cells in FHL muscle (Fig. 3). Numbers of SCs increased significantly in both Early and Late groups $24 \mathrm{~h}$ after exercise. No significant difference of SCs was found between the Early and Late groups (Fig. 3).

The circulating testosterone, corticosterone, testosterone/ corticosterone ratio (T/C ratio) and IL-6 are shown in Fig. 4. In the Early group, no increases in plasma testosterone concentration or testosterone/corticosterone ratio were observed after acute resistance exercise. However, the level of testosterone concentration and testosterone/corticosterone ratio increased significantly $2 \mathrm{~h}$ after exercise in the Late group (Fig. 4A-C). The circulating IL-6 level also increased significantly $2 \mathrm{~h}$ after exercise in the Late group. However, these increases were not observed in the Early group. The circulating IL-6 level increased significantly $24 \mathrm{~h}$ after exercise in both training groups (Fig. 4).
The muscular IL-6/STAT1/STAT3 signaling is shown in Fig. 5. IL-6 protein expression levels in muscle decreased significantly in both Early and Late groups $2 \mathrm{~h}$ after an acute bout of climbing exercise. Muscular IL- 6 in the Late group was marginally lower $(p=0.08)$ than that in the Early group $2 \mathrm{~h}$ after exercise (Fig. 5A and B). STAT1 phosphorylation level was elevated significantly 2 and $6 \mathrm{~h}$ after exercise and then returned to baseline $24 \mathrm{~h}$ after exercise. We found no significant difference in phosphorylation of STAT1 between the Early and Late groups at all measured time points (Fig. 5A and C). In the Late group, STAT3 phosphorylation levels in muscle were activated $24 \mathrm{~h}$ after exercise. However, this change did not occur in the Early group (Fig. 5A and D).

\section{Discussion}

The present study tested the hypothesis that animals are able to adapt to TOD effects on muscle mass and strength due to resistance exercise by modulating inflammation and SC recruitment. The major findings of this study are: (1) exercise in the late active period results in increases in $\mathrm{T} / \mathrm{C}$ ratio, IL-6 release and STAT3 signaling in muscle; (2) immune cell
A

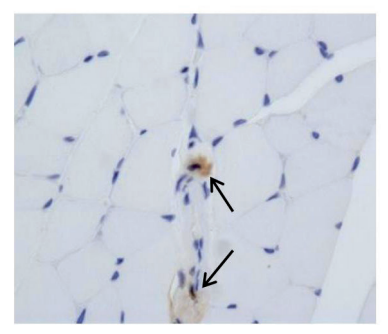

B

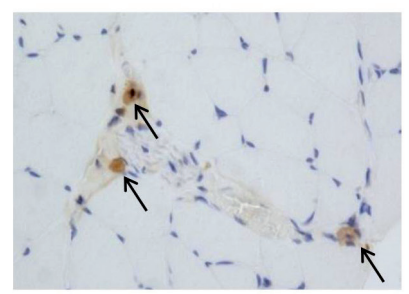

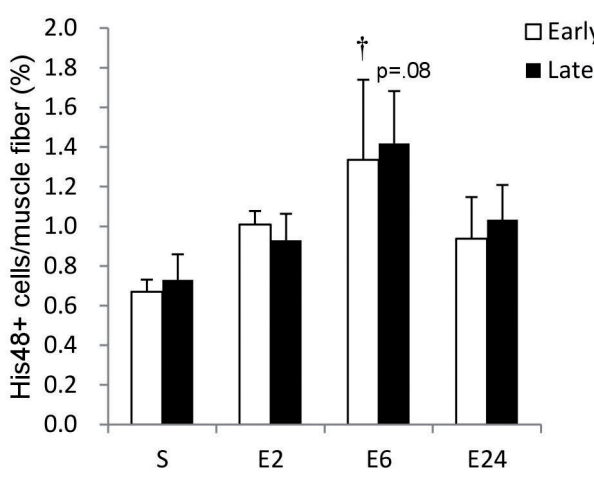

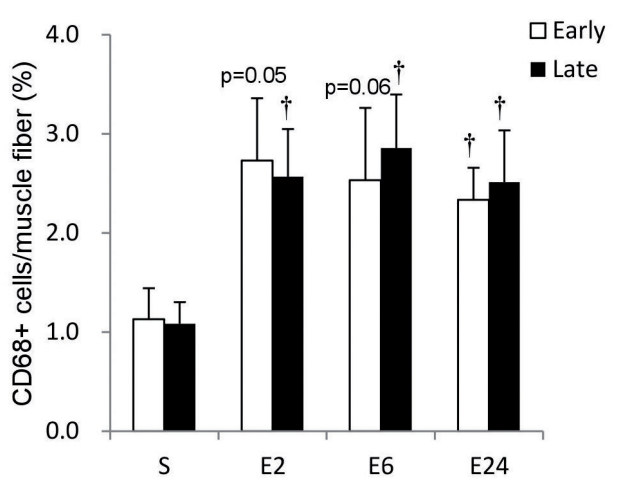

C

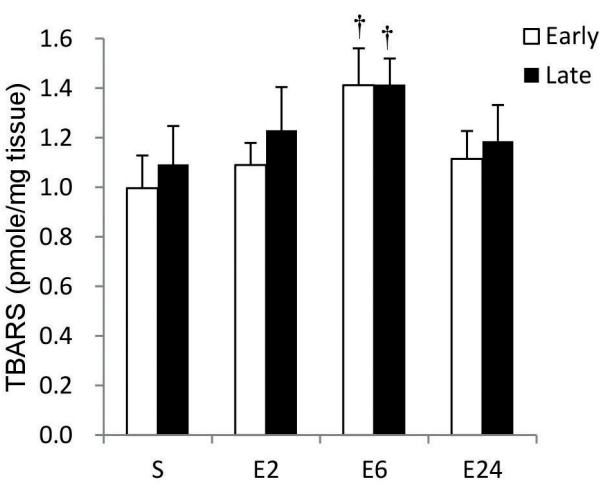

Figure 2. Neutrophil and macrophage invasion and oxidative stress in FHL muscle. Representative immunohistochemical staining (brown color) of His48-positive cells (A; arrowheads) and CD68-positive cells (B; arrowheads) in a FHL muscle section. Nucleolus was labeled with eosin staining (blue color). The scoring of His48- and CD68-positive cells is shown on the right. C. TBARS level of FHL muscle. All data are presented as the mean \pm SE. ${ }^{\dagger} p<0.05$ vs. sedentary (S) Early or Late groups. For more information, see Material and Methods. 

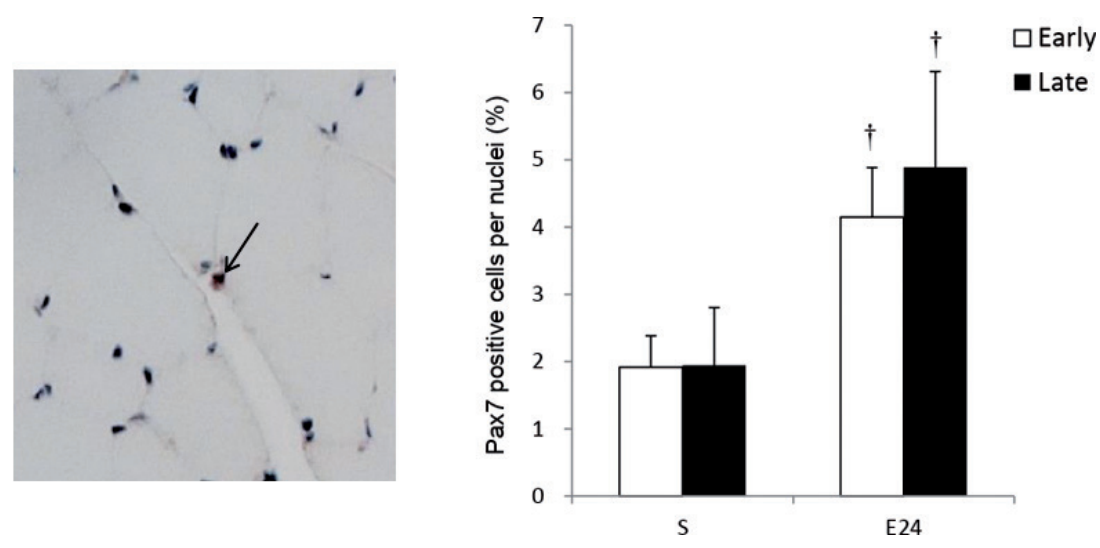

Figure 3. Satellite cells in muscle. Representative immunohistochemical staining (brown color) of Pax-7 positive cells (arrowheads) in a FHL muscle section. Data are presented in the graph as the mean \pm SE. ${ }^{\dagger} p<0.05 v s$. sedentary (S) Early or Late groups.

infiltration and SC recruitment in muscle after acute exercise were not influenced by exercise at different TOD. Both inflammation and SC recruitment play an important role in muscle hypertrophy against increased muscle load (Tidball et al. 2010). Our data supports the hypothesis of a prior publication, that the TOD may influence the hypertrophic signaling response to acute resistance exercise (Sedliak et al. 2013), and demonstrates that animals are able to adapt to different training schedules by regulating IL-6/STAT3 signaling to achieve the same training outcome in muscle mass and strength.

SCs are important stem cells responsible for exerciseinduced adaptation in muscle hypertrophy (Rosenblatt et al. 1994). In particular, the magnitude of muscle hypertrophy during resistance training is associated with the number
A

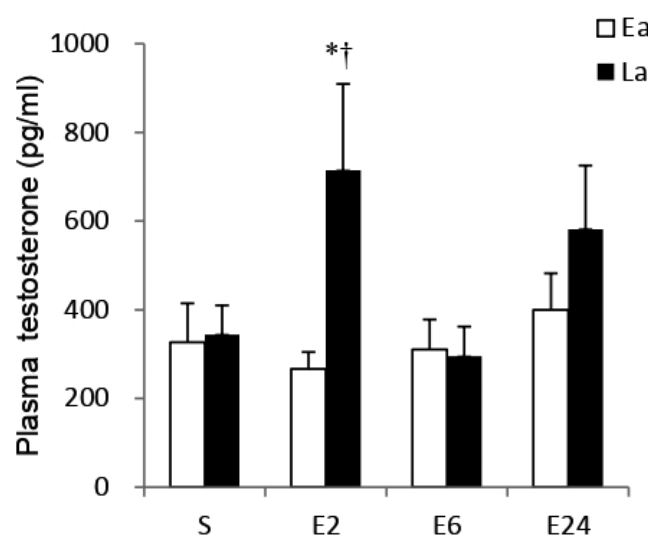

C

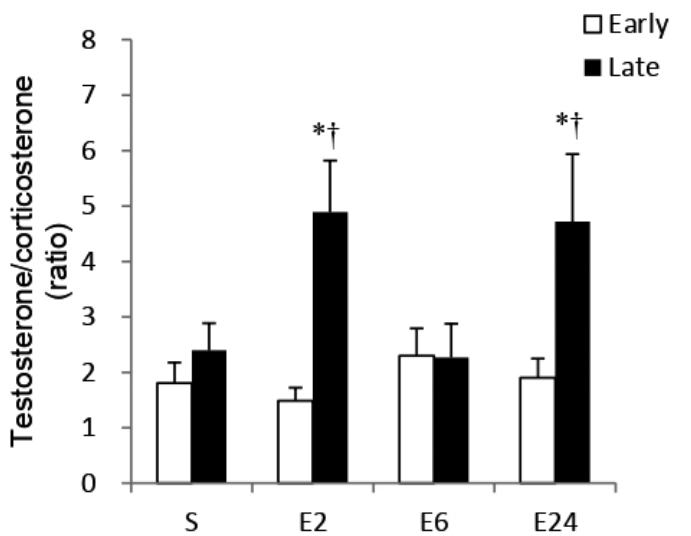

B

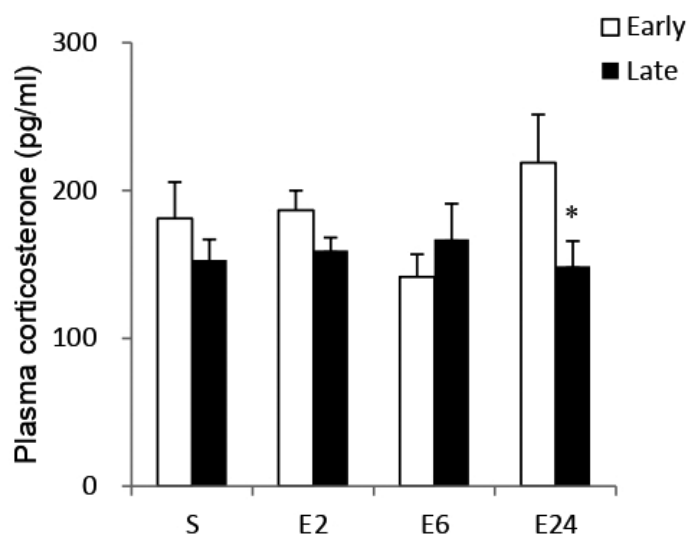

D

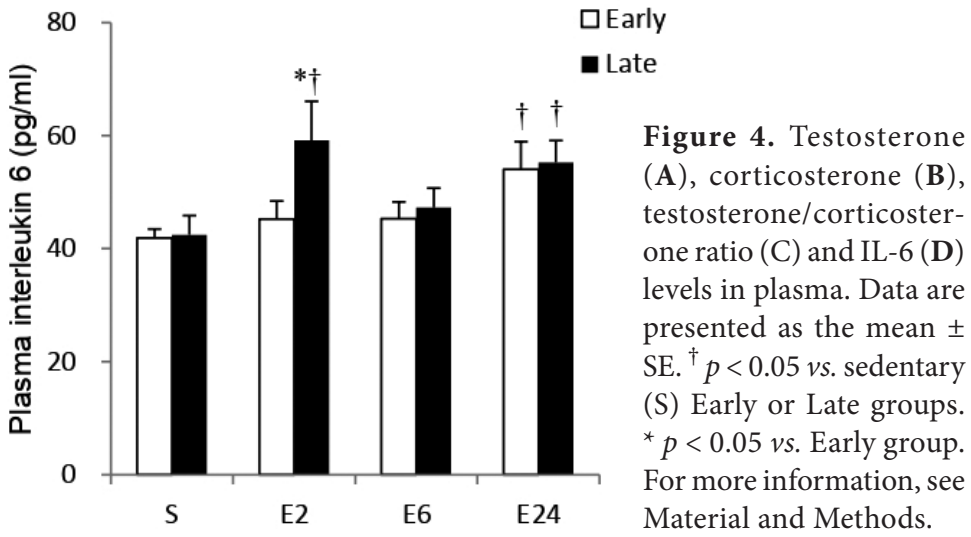


A

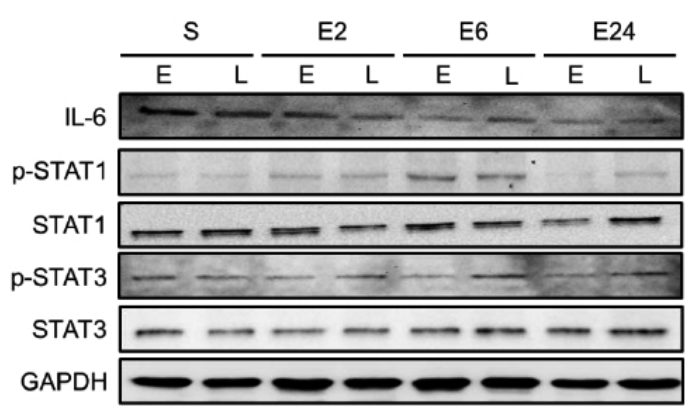

C

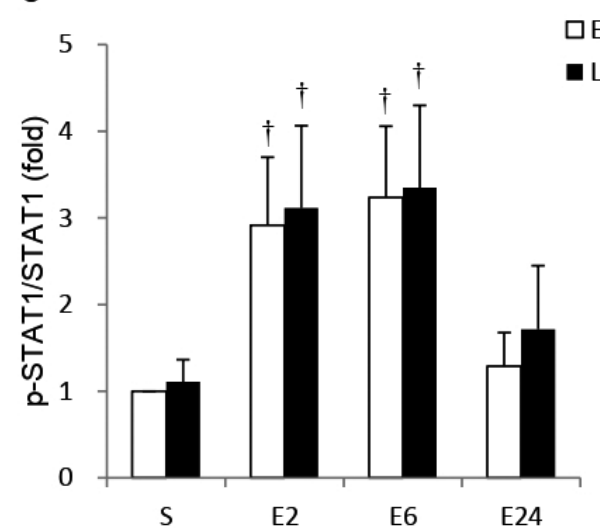

B

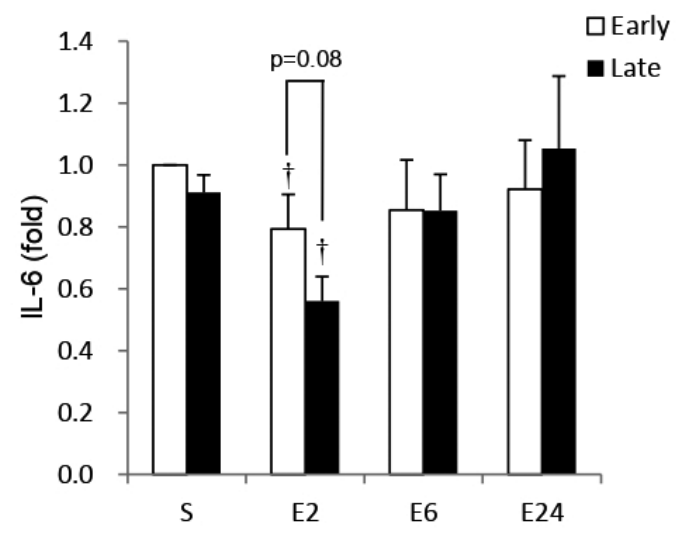

D

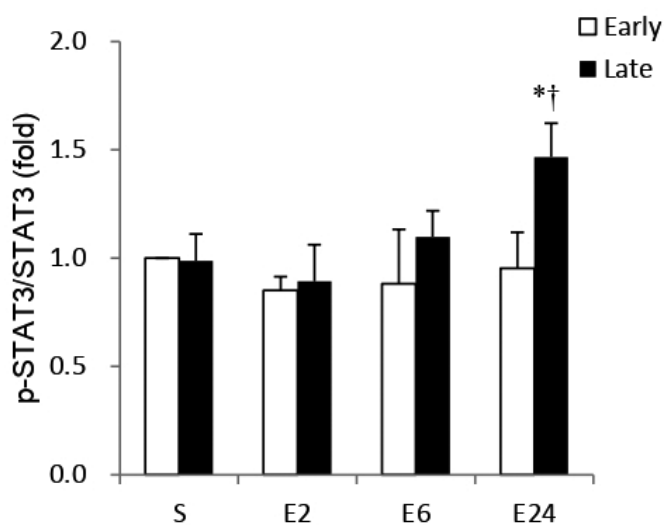

Figure 5. IL-6/STAT1/STAT3 pathway. A. Representative Western blot showing protein levels of IL-6, total STAT1, phosphorylated STAT1, total STAT3, phosphorylated STAT3 extracted from FDP muscle. Relative protein quantification of IL-6 (B), p-STAT1/STAT1 (C) and p-STAT3/STAT3 (D) normalized to GAPDH. Data are presented as the mean \pm SE. ${ }^{\dagger} p<0.05$ vs. sedentary (S) Early or Late groups. ${ }^{\star} p<0.05 v s$. Early group. For more information, see Material and Methods.

of SC recruitments (Petrella et al. 2008). SC depletion by tamoxifen has been shown to diminish synergist ablation overload-induced muscle hypertrophy in young mice (Murach et al. 2017). In this study, acute resistance exercise increased numbers of SCs in the Early and Late groups to a similar extent, evidenced by increased Pax7-positive cells in muscle tissue $24 \mathrm{~h}$ after exercise. This response is consistent with previous observations in resistance-exercised animals (Bellamy et al. 2014) and humans (Toth et al. 2011; Walker et al. 2012). In the study, the similar degree of muscle hypertrophy and strength between Early and Late groups fits well with the results of Pax7-positive cell distribution in muscle tissues. To the best of our knowledge, this is the first study to report the TOD effects on exercise-induced SC recruitment.

IL-6 is an essential mediator of SC-associated skeletal muscle hypertrophy (Serrano et al. 2008). The circulating IL-6 level is known to adjust in response to the recovery status of exercised muscle to achieve adaptation (Keller et al. 2001; Fischer et al. 2004; Yang et al. 2016). Our results demonstrate that circulating IL-6 levels in the Late group are relatively higher than those in the Early group $2 \mathrm{~h}$ after resistance exercise. This result is consistent with a previous human study which reported that sprinting exercise in the evening induced greater plasma IL-6 than exercise in the morning (Abedelmalek et al. 2013). However, another human study showed that resistance exercise in the morning caused significant increases in serum IL-6 level, whereas resistance exercise in the evening sessions exhibited no change (Pledge et al. 2011). The discrepancy among studies may be due to differences in experimental design. In addition, we found that the Late group had higher circulating IL-6 levels when compared to the Early group, conversely the Late group had lower muscle IL-6 than the Early group $2 \mathrm{~h}$ after exercise. However, previous studies have shown an increased IL-6 protein level in exercised muscle (Penkowa et al. 2003; Hiscock et al. 2004; Rosendal et al. 2005). We speculate that greater release of IL-6 from muscle to circulation in the Late group may explain the low level of IL-6 in the exercised 
muscle of the present study. The results of the studies suggest the IL-6 is dynamically regulated according to recovery status to achieve the same level of stem cell recruitment and adaptation in muscle hypertrophy.

IL-6 induced satellite cell proliferation is mediated by activation of STAT1 and STAT3 signaling to increase related gene expression (Begue et al. 2013). Our results on satellite cell-related signaling pathways agree with previous studies that reported increases in STAT1 (Begue et al. 2013) and STAT3 (Toth et al. 2011) phosphorylation after an acute bout of resistance exercise in animals. It is the first study to report the effects of time-of-day specific resistance exercise on STAT1 and STAT3 activation in muscle. An increase in STAT3 phosphorylation was observed $24 \mathrm{~h}$ after exercise only when acute resistance exercise was conducted during late active period. This acute increase in STAT3 activation in muscle of the Late group may be explained by earlier increased circulating IL-6 levels $2 \mathrm{~h}$ after exercise. However, no difference in muscular STAT1 phosphorylation was found between the Early and Late groups after acute RE.

Our results on muscle hypertrophy fit well with neutrophil and macrophage infiltration and increases of TBARS levels in skeletal muscle after exercise. Inflammation is a local response which plays a key role in the muscle adaptation, regeneration and hypertrophy in response to physical challenge and damage (Paulsen et al. 2012; Gomez-Cabrera et al. 2016). Free radicals are a potent inflammatory mediator, which can influence training adaptation (Slattery et al. 2015). In animal studies, anti-inflammatory treatment attenuated myofiber growth after a localized freeze injury (Bondesen et al. 2004), inhibited muscle hypertrophy by approximately $50 \%$ following 14 days of muscle overload by synergist ablation (Soltow et al. 2006), and blunted the increases in muscle mass in overloaded muscles (Novak et al. 2009). Local nonsteroidal anti-inflammatory treatment not only reduced inflammatory cells $\left(\mathrm{CD}^{+} 8^{+}\right)$in human skeletal muscle, but also suppressed SC activation during recovery after unaccustomed eccentric exercise (Mikkelsen et al. 2009). Furthermore, the inflammatory response is regulated rigorously by the circadian system (Carter et al. 2016). For example, an animal study showed that a Streptococcus pneumoniae infection in the morning caused higher pulmonary neutrophil levels than that in the evening (Gibbs et al. 2014). However, our data show the same resulting accumulation of inflammatory cells with RE independent of time-of-day. In this study, increased His $48^{+}$neutrophil and $\mathrm{CD} 68^{+}$macrophage in skeletal muscle with RE intervention are consistent with the observed increase in muscle hypertrophy. Taken together, these increases may explain the same outcomes following RE interventions at different TOD. To the best of our knowledge, it is the first study demonstrating the circadian effect of RE on inflammatory cell infiltration into muscle tissue.
Diurnal rhythmic fluctuation in testosterone and glucocorticoids are well documented (Collomp et al. 2016). In the present study, our data show that RE in the late active period significantly increased testosterone level and $\mathrm{T} / \mathrm{C}$ ratio. These results are consistent with previous studies (Bird et al. 2004). Testosterone is an anabolic hormone that promotes muscle hypertrophy, and this response is associated with SC proliferation (Sinha-Hikim et al. 2003, 2006). However, higher testosterone levels in the Late group after RE are not related to the muscle CSA and Pax7+ cell number. On the other hand, testosterone plays an important role in inhibition of inflammatory response, evidenced by an inverse association between serum testosterone and blood leukocyte count in men (Park et al. 2018). In another study, oral administration of testosterone reduced inflammatory markers in humans (Maggio et al. 2005). Taken together, the higher testosterone may be a negative feedback response aimed at decreasing systemic inflammation. Consequently, there were no significant differences in inflammatory cell accumulation in skeletal muscle between the two groups. Glucocorticoids are also anti-inflammatory steroid hormones (Petrovsky et al. 1998) that display high concentrations in the morning in humans (Bonato et al. 2017). Our results also reflect the higher level of circulating corticosterone $24 \mathrm{~h}$ after RE in the early active period, which corresponds to morning time of humans.

Our data confirms a study conducted by Sedliak et al. (2009), who reported no significant difference of increased CSA and 1-RM of quadriceps femoris (QF) muscle after 10 weeks resistance training between the morning and afternoon training groups. However, another human study of Küüsmaa et al. (2016) indicated that training in the evening gained more muscle mass compared to training in the morning only during the training weeks $13-24$, but not in weeks $0-12$ (Küüsmaa et al. 2016). Therefore, we do not rule out the possibility that the training period may be a factor to influence the magnitude adaptations resulting from time-of-day specific training. In addition, in the present study, we measured animal muscle strength at the midpoint of the active period. However, muscle strength is also influenced by different time-of-day (Atkinson et al. 1996). Unfortunately, we have no measurements of the muscle strength at different time-of-day.

\section{Conclusion}

The aim of this study was to investigate the time-of-day specific effects on adaptations to RE. We observed performing RE during late active periods induced higher IL-6/STAT3 signaling in skeletal muscle, but there were no significant group differences in satellite cell proliferation or muscle hypertrophy after 10 weeks RE. These ambiguous results appear to show that animals can adapt to resistance training during different time-of-day, by modulating inflammatory signaling of skeletal muscle. 
Acknowledgement. The authors acknowledge financial support from Taipei Medical University (TMU103-AE1-B10), and the Ministry of Science and Technology (104-2410-H-197-001-), Taiwan, Republic of China (ROC).

\section{References}

Abedelmalek S, Chtourou H, Aloui A, Aouichaoui C, Souissi N, Tabka Z (2013): Effect of time of day and partial sleep deprivation on plasma concentrations of IL- 6 during a short-term maximal performance. Eur. J. Appl. Physiol. 113, 241-248 https://doi.org/10.1007/s00421-012-2432-7

Almada AE, Wagers AJ (2016): Molecular circuitry of stem cell fate in skeletal muscle regeneration, ageing and disease. Nat. Rev. Mol. Cell Biol. 17, 267-279

https://doi.org/10.1038/nrm.2016.7

Atkinson G, Reilly T (1996): Circadian variation in sports performance. Sports Med. 21, 292-312 https://doi.org/10.2165/00007256-199621040-00005

Begue G, Douillard A, Galbes O, Rossano B, Vernus B, Candau R, Py G (2013): Early activation of rat skeletal muscle IL-6/STAT1/ STAT3 dependent gene expression in resistance exercise linked to hypertrophy. PloS One 8, e57141 https://doi.org/10.1371/journal.pone.0057141

Bellamy LM, Joanisse S, Grubb A, Mitchell CJ, McKay BR, Phillips SM, Baker S, Parise G (2014): The acute satellite cell response and skeletal muscle hypertrophy following resistance training. PLoS One 9, e109739 https://doi.org/10.1371/journal.pone.0109739

Bird SP, Tarpenning KM (2004): Influence of circadian time structure on acute hormonal responses to a single bout of heavy-resistance exercise in weight-trained men. Chronobiol. Int. 21, 131-146 https://doi.org/10.1081/CBI-120027987

Bonato M, La Torre A, Saresella M, Marventano I, Merati G, Vitale JA (2017): Salivary cortisol concentration after high-intensity interval exercise: Time of day and chronotype effect. Chronobiol. Int. 34, 1-10 https://doi.org/10.1080/07420528.2017.1311336

Bondesen BA, Mills ST, Kegley KM, Pavlath GK (2004): The COX2 pathway is essential during early stages of skeletal muscle regeneration. Am. J. Physiol. Cell Physiol. 287, C475-C483 https://doi.org/10.1152/ajpcell.00088.2004

Carter SJ, Durrington HJ, Gibbs JE, Blaikley J, Loudon AS, Ray DW, Sabroe I (2016): A matter of time: study of circadian clocks and their role in inflammation. J. Leukoc. Biol. 99, 549-560 https://doi.org/10.1189/jlb.3RU1015-451R

Chtourou H, Souissi N (2012): The effect of training at a specific time of day: A review. J. Strength Cond. Res. 26, 1984-2005 https://doi.org/10.1519/JSC.0b013e31825770a7

Collomp K, Baillot A, Forget H, Coquerel A, Rieth N, VibarelRebot N (2016): Altered diurnal pattern of steroid hormones in relation to various behaviors, external factors and pathologies: A review. Physiol. Behav. 164, 68-85 https://doi.org/10.1016/j.physbeh.2016.05.039

Fischer CP, Hiscock NJ, Penkowa M, Basu S, Vessby B, Kallner A, Sjöberg LB, Pedersen BK (2004): Supplementation with vitamins $\mathrm{C}$ and $\mathrm{E}$ inhibits the release of interleukin-6 from contracting human skeletal muscle. J. Physiol. 558, 633-645 https://doi.org/10.1113/jphysiol.2004.066779

Gibbs J, Ince L, Matthews L, Mei J, Bell T, Yang N, Saer B, Begley N, Poolman T, Pariollaud M (2014): An epithelial circadian clock controls pulmonary inflammation and glucocorticoid action. Nat. Med. 20, 919-926 https://doi.org/10.1038/nm.3599

Gomez-Cabrera MC, Viña J, Ji LL (2016): Role of redox signaling and inflammation in skeletal muscle adaptations to training. Antioxidants 5, 48 https://doi.org/10.3390/antiox5040048

Gonzalez AM, Hoffman JR, Stout JR, Fukuda DH, Willoughby DS (2016): Intramuscular anabolic signaling and endocrine response following resistance exercise: implications for muscle hypertrophy. Sports Med. 46, 671-685 https://doi.org/10.1007/s40279-015-0450-4

Hiscock N, Chan MS, Bisucci T, Darby IA, Febbraio MA (2004): Skeletal myocytes are a source of interleukin- 6 mRNA expression and protein release during contraction: evidence of fiber type specificity. FASEB J. 18, 992-994 https://doi.org/10.1096/fj.03-1259fje

Hornberger Jr TA, Farrar RP (2004): Physiological hypertrophy of the FHL muscle following 8 weeks of progressive resistance exercise in the rat. Can. J. Appl. Physiol. 29, 16-31 https://doi.org/10.1139/h04-002

Küüsmaa M, Schumann M, Sedliak M, Kraemer WJ, Newton RU, Malinen J-P, Nyman K, Häkkinen A, Häkkinen K (2016): Effects of morning versus evening combined strength and endurance training on physical performance, muscle hypertrophy, and serum hormone concentrations. Appl. Physiol. Nutr. Metab. 41, 1285-1294 https://doi.org/10.1139/apnm-2016-0271

Keller C, Steensberg A, Pilegaard H, Osada T, Saltin B, Pedersen BK, Neufer PD (2001): Transcriptional activation of the IL-6 gene in human contracting skeletal muscle: influence of muscle glycogen content. FASEB J. 15, 2748-2750 https://doi.org/10.1096/fj.01-0507fje

Maggio M, Basaria S, Ceda GP, Ble A, Ling SM, Bandinelli S, Valenti G, Ferrucci L (2005): The relationship between testosterone and molecular markers of inflammation in older men. J. Endocrinol. Invest. 28, 116-119

Mikkelsen UR, Langberg H, Helmark IC, Skovgaard D, Andersen LL, Kjaer M, Mackey AL (2009): Local NSAID infusion inhibits satellite cell proliferation in human skeletal muscle after eccentric exercise. J. Appl. Physiol. 107, 1600-1611 https://doi.org/10.1152/japplphysiol.00707.2009

Murach KA, White SH, Wen Y, Ho A, Dupont-Versteegden EE, McCarthy JJ, Peterson CA (2017): Differential requirement for satellite cells during overload-induced muscle hypertrophy in growing versus mature mice. Skelet. Muscle 7, 14 https://doi.org/10.1186/s13395-017-0132-z

Novak ML, Billich W, Smith SM, Sukhija KB, McLoughlin TJ, Hornberger TA, Koh TJ (2009): COX-2 inhibitor reduces skeletal muscle hypertrophy in mice. Am. J. Physiol. Regul. Integr. Comp. Physiol. 296, R1132-R1139 https://doi.org/10.1152/ajpregu.90874.2008

Park B, Lee YJ (2018): Inverse association of testosterone and sex hormone binding globulin levels with leukocyte count in middle-aged and elderly men. The Aging Male 21, 1-6 
https://doi.org/10.1080/13685538.2018.1477934

Paulsen G, Ramer Mikkelsen U, Raastad T, Peake JM (2012): Leucocytes, cytokines and satellite cells: what role do they play in muscle damage and regeneration following eccentric exercise? Exerc. Immunol. Rev. 18, 42-97

Pedersen BK, Fischer CP (2007): Beneficial health effects of exercise-the role of IL-6 as a myokine. Trends Pharmacol. Sci. 28, $152-156$ https://doi.org/10.1016/j.tips.2007.02.002

Penkowa M, Keller C, Keller P, Jauffred S, Pedersen BK (2003): Immunohistochemical detection of interleukin- 6 in human skeletal muscle fibers following exercise. FASEB J. 17, 2166-2168 https://doi.org/10.1096/fj.03-0311fje

Petrella JK, Kim JS, Mayhew DL, Cross JM, Bamman MM (2008): Potent myofiber hypertrophy during resistance training in humans is associated with satellite cell-mediated myonuclear addition: a cluster analysis. J. Appl. Physiol. 104, 1736-1742 https://doi.org/10.1152/japplphysiol.01215.2007

Petrovsky N, McNair P, Harrison LC (1998): Diurnal rhythms of pro-inflammatory cytokines: regulation by plasma cortisol and therapeutic implications. Cytokine 10, 307-312 https://doi.org/10.1006/cyto.1997.0289

Pledge D, Grosset J-F, Onambélé-Pearson GL (2011): Is there a morning-to-evening difference in the acute IL- 6 and cortisol responses to resistance exercise? Cytokine 55, 318-323 https://doi.org/10.1016/j.cyto.2011.05.005

Rosenblatt JD, Yong D, Parry DJ (1994): Satellite cell activity is required for hypertrophy of overloaded adult rat muscle. Muscle Nerve 17, 608-613 https://doi.org/10.1002/mus.880170607

Rosendal L, Søgaard K, Kjaer M, Sjøgaard G, Langberg H, Kristiansen J (2005): Increase in interstitial interleukin-6 of human skeletal muscle with repetitive low-force exercise. J. Appl. Physiol. 98, 477-481

https://doi.org/10.1152/japplphysiol.00130.2004

Sedliak M, Finni T, Cheng S, Lind M, Häkkinen K (2009): Effect of time-of-day-specific strength training on muscular hypertrophy in men. J. Strength Cond. Res. 23, 2451-2457 https://doi.org/10.1519/JSC.0b013e3181bb7388

Sedliak M, Zeman M, Buzgó G, Cvečka J, Hamar D, Laczo E, Zelko A, Okuliarová M, Raastad T, Nilsen TS (2013): Effects of time of day on resistance exercise-induced anabolic signaling in skeletal muscle. Biol. Rhythm Res. 44, 756-770 https://doi.org/10.1080/09291016.2012.740314

Sedliak M, Zeman M, Buzgó G, Cvecka J, Hamar D, Laczo E, Okuliarova M, Vanderka M, Kampmiller T, Häkkinen K (2018): Morphological, molecular and hormonal adaptations to early morning versus afternoon resistance training. Chronobiol. Int. 35, 450-464 https://doi.org/10.1080/07420528.2017.1411360

Serrano AL, Baeza-Raja B, Perdiguero E, Jardí M, Muñoz-Cánoves $P(2008)$ : Interleukin-6 is an essential regulator of satellite cellmediated skeletal muscle hypertrophy. Cell Metab. 7, 33-44 https://doi.org/10.1016/j.cmet.2007.11.011

Sinha-Hikim I, Cornford M, Gaytan H, Lee ML, Bhasin S (2006): Effects of testosterone supplementation on skeletal muscle fiber hypertrophy and satellite cells in community-dwelling older men. J. Clin. Endocrinol. Metab. 91, 3024-3033 https://doi.org/10.1210/jc.2006-0357
Sinha-Hikim I, Roth SM, Lee MI, Bhasin S (2003): Testosteroneinduced muscle hypertrophy is associated with an increase in satellite cell number in healthy, young men. Am. J. Physiol. Endocrinol. Metab. 285, E197-E205 https://doi.org/10.1152/ajpendo.00370.2002

Slattery K, Bentley D, Coutts AJ (2015): The role of oxidative, inflammatory and neuroendocrinological systems during exercise stress in athletes: implications of antioxidant supplementation on physiological adaptation during intensified physical training. Sports Med. 45, 453-471 https://doi.org/10.1007/s40279-014-0282-7

Soltow QA, Betters JL, Sellman JE, Lira VA, Long JH, Criswell DS (2006): Ibuprofen inhibits skeletal muscle hypertrophy in rats. Med. Sci. Sports Exerc. 38, 840-846 https://doi.org/10.1249/01.mss.0000218142.98704.66

Sun LG, Ma KW, Wang HX, Xiao F, Gao Y, Zhang W, Wang KP, Gao X, Ip N, Wu ZG (2007): JAK1-STAT1-STAT3, a key pathway promoting proliferation and preventing premature differentiation of myoblasts. J. Cell Biol. 179, 129-138 https://doi.org/10.1083/jcb.200703184

Tidball JG, Villalta SA (2010): Regulatory interactions between muscle and the immune system during muscle regeneration. Am. J. Physiol. Regul. Integr. Comp. Physiol. 298, R1173-R1187 https://doi.org/10.1152/ajpregu.00735.2009

Tidball JG (2017): Regulation of muscle growth and regeneration by the immune system. Nat. Rev. Immunol. 17, 165-178 https://doi.org/10.1038/nri.2016.150

Tierney MT, Sacco A (2016): Satellite cell heterogeneity in skeletal muscle homeostasis. Trends Cell Biol. 26, 434-444 https://doi.org/10.1016/j.tcb.2016.02.004

Toth KG, McKay BR, De Lisio M, Little JP, Tarnopolsky MA, Parise G (2011): IL-6 induced STAT3 signalling is associated with the proliferation of human muscle satellite cells following acute muscle damage. PLoS One 6, e17392 https://doi.org/10.1371/journal.pone.0017392

Trenerry MK, Della Gatta PA, Larsen AE, Garnham AP, Cameron-Smith D (2011): Impact of resistance exercise training on interleukin-6 and JAK/STAT in young men. Muscle Nerve 43, 385-392 https://doi.org/10.1002/mus.21875

Walker DK, Fry CS, Drummond MJ, Dickinson JM, Timmerman KL, Gundermann DM, Jennings K, Volpi E, Rasmussen BB (2012): PAX7+ satellite cells in young and older adults following resistance exercise. Muscle Nerve 46, 51-59 https://doi.org/10.1002/mus.23266

Yang SC, Wang CC, Lee SD, Lee YU, Chan KH, Chen YL, Fogt DL, Kuo CH (2016): Impact of 12-s rule on performance and muscle damage of baseball pitchers. Med. Sci. Sports Exerc. 48, 2512-2516

https://doi.org/10.1249/MSS.0000000000001048

Zhang C, Li Y, Wu Y, Wang L, Wang X, Du J (2013): Interleukin-6/signal transducer and activator of transcription 3 (STAT3) pathway is essential for macrophage infiltration and myoblast proliferation during muscle regeneration. J. Biol. Chem. 288, 1489-1499 https://doi.org/10.1074/jbc.M112.419788

Received: July 17, 2019

Final version accepted: October 18, 2019 